\title{
Retinal detachment in median cleft-face syndrome
}

\author{
V. FEILER-OFRY, V. GODEL, P. NEMET, AND M. LAZAR \\ From the Department of Ophthalmology, Ichilov Hospital, and \\ Tel Aviv University School of Medicine, Israel
}

SUMmARY A 7-year-old boy had an unusual association of median cleft-face syndrome, a characteristic physiognomy, unilateral retinal dysplasia, and bilateral retinal detachment. Despite surgical treatment to both eyes he became blind. The hereditary pattern operating in this complex disorder was found to be consistent with an autosomal dominant trait.

The occurrence of retinal detachment in median facial defects has been described in syndromes which differ both in morphology and in the mode of inheritance. These anomalies appear from the literature to be causally and pathogenetically related, through a concomitant developmental defect.

The present report concerns a family pedigree in which 1 boy presented with a median cleft-face syndrome $^{1}$ associated with primary retinal dysplasia in 1 eye, later developing bilateral blinding retinal detachments.

\section{Case report}

The initial contact with the proband (Fig. 1, II-6) was in 1972, when at the age of 5 he was brought to hospital urgently with a history of loss of vision in his good right eye. His medical history revealed that shortly after birth he had difficulty in breathing and was found to suffer from median cleft nose, median cleft upper lip, and complete cleft palate. Later he underwent a surgical correction for his midfacial defects. He had had a normal gestation and delivery, had been a full-term child and did not require oxygen therapy during infancy. His mother had not been exposed to teratogenic factors during the gestational period. Three years before the onset of the visual symptoms he underwent an eye examination and was found to have a high myopia $(-14.0 \mathrm{D})$. The corrected visual acuity in the right eye was $20 / 80$. The left eye was found to have no potentially useful vision and was diagnosed as having retinal dysplasia.

The eye examination when he was in hospital disclosed a visual acuity of $1 / 20$ in the right eye and

Correspondence to V. Feiler-Ofry, MD, Department of Ophthalmology, Ichilov Hospital, Tel Aviv, Israel.

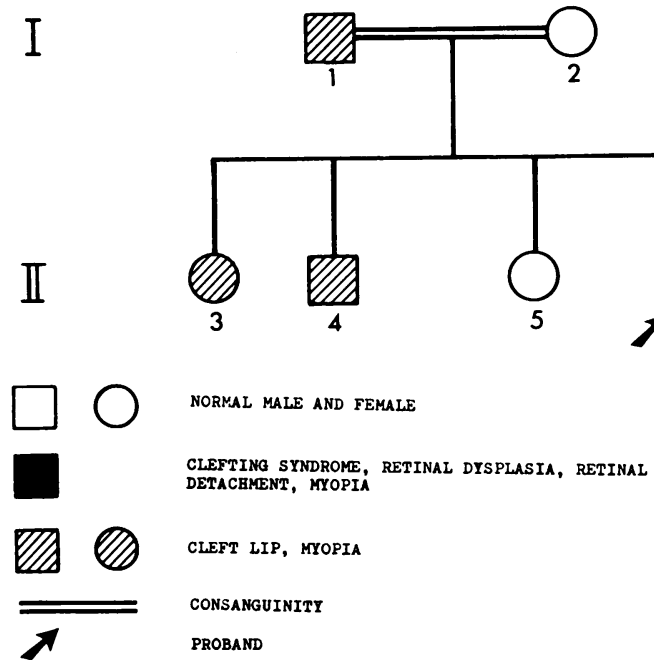

Fig. 1 Family pedigree

only hand movements in the left. The anterior segments appeared normal except for a slight left enophthalmos. The intraocular pressure was 10 $\mathrm{mmHg}$. There was normal movement of the globes in all positions of gaze. Sluggish pupillary reflexes were obtained, but the pupils dilated reasonably well. The lenses were clear.

Ophthalmoscopic examination showed a right bullous rhegmatogenous retinal detachment, with multiple retinal tears and holes, extending from the periphery to the optic disc in all the quadrants, partially sparing the macula. Translucent strands and vitreal liquefaction gave the impression of an optically empty vitreous cavity. In the left fundus a proliferative whitish fibrous tissue emanating from the optic disc was found. This patchy proliferative tissue, extending to the temporal upper periphery, was surrounded by scattered pigmentary clumps 


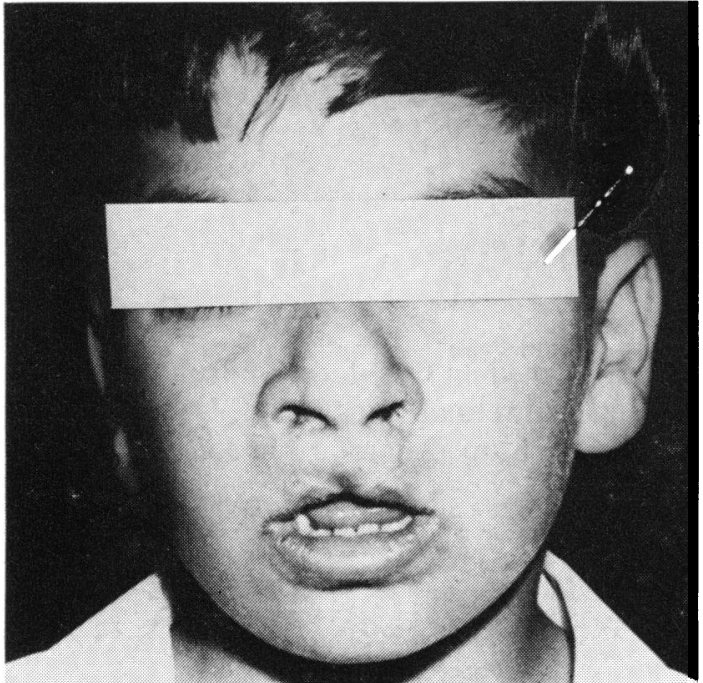

Fig. 2 Frontal view of the proband's face. Note the corrected midfacial defects and the broad nasal bridge

and ended in a veil-like retinal fold. The lower retinal part was completely detached, with massive periretinal proliferation.

Repair of the right detached retina was attempted with a wide scleral trapdoor, diathermy in the bed, a $12 \mathrm{~mm}$ silicone tire, an encircling band, drainage of subretinal fluid, and intravitreal injection. The retina was flat for 3 days after operation, but became detached again soon afterwards, developing periretinal membranes with funnel-shaped fixed folds. A second attempt at repair was unsuccessful. After the failure in the right eye surgical repair of the left eye was performed, but despite the intervention this eye too remained inoperably blind.

As the retinal findings were found to be associated with median facial defects, a complete medical examination was carried out. Physically the child was in good health. Significant findings were confined to the face. The frontal view revealed hypertelorism, with interpupillary distances falling only slightly above the upper limits of the normal. Only a rudimentary remaining defect of his upper lip and nose was noted (Fig. 2). A characteristic maxillary hypoplasia with the nasal defect gave the appearance of a flattened mid-face (Fig. 3). The remainder of the physical examinations of the skeleton and chest, routine laboratory examinations, and a chromosomal analysis were normal. The child's mentality was considered to be borderline.

The family history revealed that the parents were consanguineously related, being first cousins. The father (Fig. 1 I-1) had a surgically corrected cleft lip and was myopic $(-5 \cdot 0 \mathrm{D})$. Neither parent had

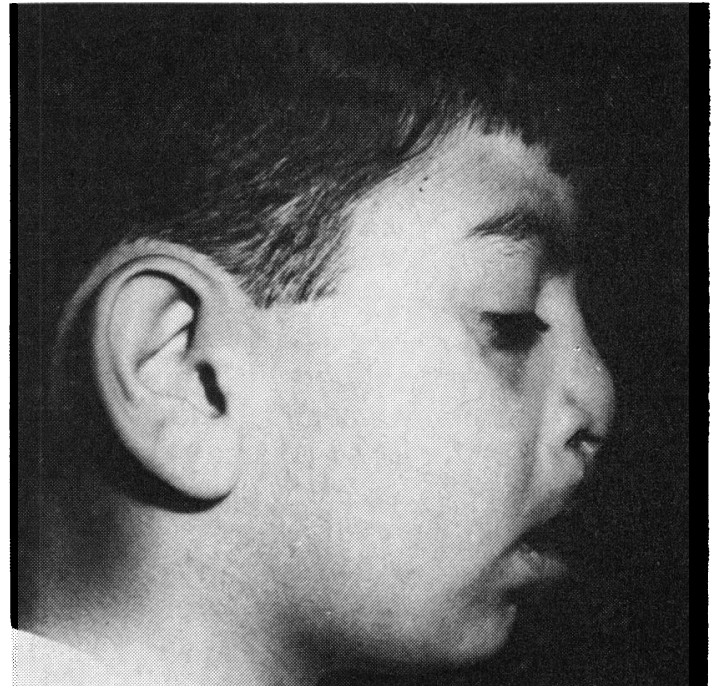

Fig. 3 The characteristic physiognomy with the midfacial flattening

any other special diseases. They had 2 other mildly myopic children born with cleft lips, later surgically corrected (Fig. 1 II-3, II-4). Another physically healthy daughter presented no median face defects and was found to be emetropric (Fig. 1 II-5). An inquiry among the family members of the parents revealed that no others had showed similar findings.

\section{Discussion}

Retinal detachment in connection with malformations of the face has been found frequently enough to establish clearly that we are dealing with syndromes rather than fortuitous associations. ${ }^{2-4}$ The literature contains a confusing multitude of variant syndromes in which vitreoretinal degeneration and median cleft-face defects are associated with a variety of additional systemic anomalies. ${ }^{5-7}$ The clinical variability of these defects and their familial aggregations give considerable support to the assumption that genetic factors play an important role in their aetiology.

In our case the median facial defects and the characteristic physiognomy consisting of maxillary hypoplasia, the broad nasal bridge, and midfacia flattening was associated with unilateral retinal dysplasia, a joint occurrence which is certainly rare. No reports of an association between retinal dysplasia and cleft defects have been found except complex disorders such as Meckel syndrome ${ }^{8}$ or chromosomal aberrations. ${ }^{9}$ The severe vitreous changes in the form of liquefaction and preretinal membrane formation in the patient's highly myopic 
eyes were complicated by bilateral retinal detachments. Surgical repair had been attempted, but despite all treatments both eyes became inoperably blind, confirming previous similar impressions..$^{10}$ These failures after conventional encircling techniques suggested the possibility of poor retinal tissue response to surgery, particularly when it was not followed by vitrectomy.11

The midfacial defects found in the father and the patient's sibs were helpful in tracing the path of the mutant gene in the pedigree. The most likely mode of inheritance in this family seemed to follow autosomal dominant transmission. The pedigree shows that a minimally affected parent may have a severely affected offspring and that the symptoms appeared in members of 2 successive generations, with both sexes affected. Interestingly a consanguineous mating between the affected father and his phenotypically normal cousin-the mother-took place. Three classes of offsprings were expected among the progeny of this union, namely, homozygous normal, heterozygous affected, and homozygous affected, in a distribution of $1: 2: 1$ respectively. This prediction seems to have been realised in that 1 child appears to be unaffected (II-5), 2 others (II-3, II-4) display lesions of mild severity similar to that of their father's (I-1) and 1 is affected much more severely (II-6), suggesting homozygosity for the gene. If we reject such a hypothesis, it is difficult to conceive any simple explanation for the distribution of the defects in this pedigree.

All the previously described dominant syndromes of this kind, like Wagner syndrome, ${ }^{12}$ Stickler syndrome, ${ }^{5}$ Cervenka syndrome, ${ }^{2}$ and others present identical vitreoretinal findings, the difference in the clinical appearance depending merely on the variability of the associated systemic defects. Their similar clinical manifestations and inheritance seem to confirm the validity of the concept that all these syndromes are fundamentally related diseases representing deviating manifestations of the same kind of mutant gene. ${ }^{13}$

As the nature of these anomalies remains in part obscure, it is evident that further understanding of these complex disorders requires the investigation of additional cases.

\section{References}

${ }^{1}$ De Mayer W. The median cleft-face syndrome. Neurology 1967; 17: 961-71.

${ }^{2}$ Cohen M, Knobloch W, Gorlin RJ. A dominantly inherited syndrome of hyaloideo retinal degeneration, cleft palate and maxillary hypoplasia (Cervenka syndrome). Birth Defects 1971; 7: 83-91.

${ }^{3}$ Delaney WV, Podedworny W, Havener WH. Inherited retinal detachment. Arch Ophthalmol 1963; 69: 44-50.

${ }^{4}$ van Balen AT, Falger ELF. Hereditary hyaloideoretinal degeneration and palatoschisis. Arch Ophthalmol 1970; 83: 152-62.

${ }^{5}$ Stickler GB, Belau PG, Farell FJ, Pugh DG, Steinberg AG, Ward LE. Hereditary progressive arthroophthalmopathy. Proc Mayo Clin 1965; 40: 433-55.

${ }^{6}$ Daniel R, Kanski JJ, Glasspool MG. Hyaloretinopathy in the clefting syndrome. Br J Ophthalmol 1974; 58: 96102.

${ }^{7} \mathrm{Knobloch}$ WH, Layer JM. Clefting syndromes associated with retinal detachment. Am J Ophthalmol 1972; 73: 517-30.

${ }^{8}$ Opitz JN, Howe JJ. The Meckel syndrome. Birth Defects 1967; 5: 167-76.

${ }^{9}$ Yanoff M, Frayer WC, Sheie HG. Ocular findings in a patient with 13-15 trisomy. Arch Ophthalmol 1963; 70: 372-5.

${ }^{10}$ Hirose T, Lee KY, Schepens CL. Wagner's hereditary vitreoretinal degeneration and retinal detachment. Arch Ophthalmol 1973; 89: 176-85.

"Brown GC, Tasman WS. Vitrectomy and Wagner's vitreoretinal degeneration. Am J Ophthalmol 1978; 86: 485-8.

${ }^{12}$ Wagner H. Ein bisher unbekanntes Erbleiden des Auges (degeneratio hyaloideo-retinalis hereditaria), beobachtet im Kanton Zürich. Klin Monatsbl Augenheilkd 1938; 100: 840-57.

${ }^{13}$ Hall JG, Herrod H. The Stickler syndrome presenting as a dominantly inherited cleft palate and blindness. J Med Genet 1975 ; 12: 397-400. 